\title{
SONETOS ITALIANOS
}

Traducidos por Clemente Althaus (1)

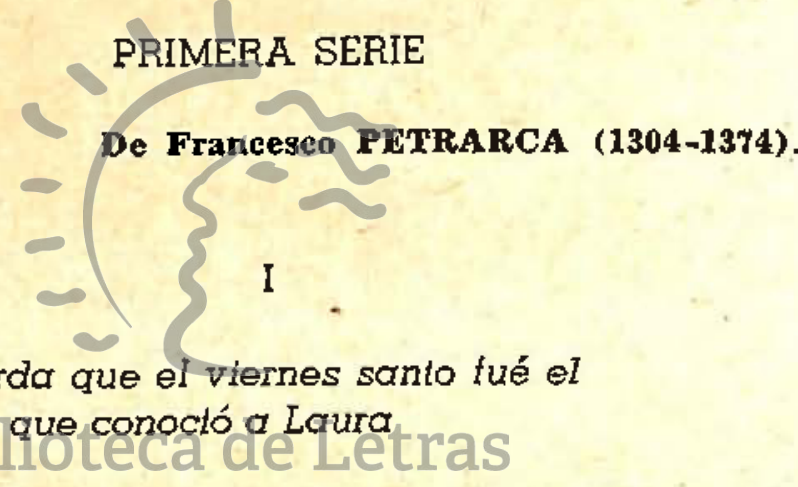

Eráceldíden queceli sobse/puso un velo

Para llorar de su Hacedor la muerte,

Cuando me ataron con cadena fuerte

Vuestros soles, que eclipsan al del cielo

Fué en el tiempo, e iba sin recelo

De que Cupido con su arpón me acierte, Curndo coutivo me sentí, de suerte Que entre el duelo común nació mi duelo.

(1) La primera y la segunda serie de estos Sonetos Italianos se publicaron por primera vez en el periódico diario La Patria, de Lima, el 5 de noviembre de 2873 . Se volvieron a reproducir esas dos series en el diario El Comercio de Lima, en las ediciones del 14 y 17 de marzo de 1874, adicionándoseles una tercera serie. En esta segunda publicación de El Comercio, se introdujeron en las dos primeras series de sonetos algunas variantes de interés crítico, que anotamos en cada verso modificado. 
Hallóme Amor del todo desarmado, y viendo abierta al corazón la vía. Por los ojos entró con desenfado.

Pero ningún honor hace, $\alpha$ fé mía, A él herirme con flecha en tal estado $Y$ a vos disimular el arma impía.

\section{BELLEZA DE LAURA}

Volaba la dorada cabellera

A Laura que en mil nudos la envolvía.

$Y$ de los ojos el fulgor ardía.

Como el sol en mitad de su carrera.

5. De su piedad, o falsa o verdadera,

En el color de su rostro se teñía:

Yo que al amor dispuesto me sentía,

¿Qué mucho fué que de improviso ardiera.

No era "su leve andar humana cosar,

10 sino de forma angélica y volonte;

No mortal parecía, sino diosa:

Y al mirarla así sola semejante

Por lo bella, modesta y pudorosa.

Yo ser juraba su inmortal amante.

La versión que publicamos de las dos primeras series es la de La Patria (1873) anotando las variantes introducidas en la publicación de El Comercio (1874). Transcribimos las variantes - que suponen cambios de criterio en el traductor, afanoso de lograr la perfección del traslado- por considerarlas reveladoras de la inquietud del autor de la versión y dado que entre las dos publicaciones sólo media un lapsa de 5 meses escasos.

(a) Vuestros ojos, que son soles del cielo. (1874).

(b) $\mathrm{Y}$ aprisionado me sentí, de suerte (1874). 


\section{III}

\section{VERGUENZA AMOROSA}

Lleno de una ilusión que me desvía De todos, y me aisla en este suelo, Aún de mi mismo recatarme suelo, Buscando a aquella que esquivar debía.

Llega con tom suave altánería.

Que el alma tiembla para alzar su vuelo:

¡Tantos suspiros trae y tanto duelo

Esta enemiga del amor y míal

Tal vez un rayo de piedad, divino,

Que brillar en sus ojos me parece, Hace que en parte mi temor se venza.

Mas, cuando habrarla $\alpha$ fin me determino, Cuando pensé olvidando, me enmudece. De casto amor la natural vergilenzal

\section{IV}

EN PRESENCIA DE LAURA NO PUEDE HABLAR NI LLORAR NI RESPIRAR

El conservarte pura de mentira

$Y$ haberte siempre cuanto pude honrado

1Qué mal, ingrata lengua, me has pagado,

Causóndome tal vez vergüenza e iral

En faz de Laura tu valor expira

Para pedir merced, $y$ o te has callado.

$O$ imperfectas palabras balbuceando.

Como de hombre que sueña o que delira.

¡Lágrimas tristes que la noche entera

Fieles me acompañáis ¿por qué delante

De mi Laura no puedo desparciros?

(c) Encadena mi labio y me enmudece (1874).

(d) El conservarte limpia de mentira (1874). 
Y vosotros, oh férvidos suspiros,

También enmudecéis de tal manera

Que solo habla mi pálido semblante!

V

\section{LA NOCHE Y LA AURORA}

Desear la noche y maldecir la aurora

Acostumbran los prósperos amontes:

Mas la noche mis duelos más punzantes

Hace, y los templa el alba bienhechora.

Pues en ella tal vez abren a una hora

Un sol y el otro como dos levantes,

en belleza $\mathrm{y}$ en luz ian semejantes,

Que el cielo de la tierra se enamora.

La noche anhela el amador amado

10 Que en sus tinieblas, de su dulce amiga

Gozar espera el carinoso lado:

Mas yo es justo que siempre la maldiga,

Pues en ella mi sueño idolatrado

$\mathrm{Su}$ cruda ausenciacả lamentar me obliga.

VI

\section{LAURA EN EL CIELO}

Me alzó mi mente a la feliz esfera

Que a los que amaron en su edén encierra;

Yo a la que busco y no hallo aquí en la tierra

Ví mós hermosa y menos altonera.

(e) Mañana me es más consoladora (1874).

(f) Que en ella suelen a la misma hora

Aparecer dos soles deslumbrantes (1874).

(g) La noche llame el amador amado (1874).

(h) Me alzó mi mente a la tercer esfera

Que a los que amaron castamente encierra;

$\mathrm{X}$ a la que busco y no hallo aquí en la tierra (1874). 
Asió mi mamo, y dijo: "Aquí te espera

Conmigo amor, mi anhelar no yerra:

Yo soy la que te dió tan cruda guerra

$\mathrm{Y}$ de su edad murió en la primavera.

10

"Mi bien no cabe en pensamiento humano:

Tú solo faltas y el mortal vestido

que tanto amaste, y que dejé en el suelo"

¿Por qué, callando, me soltó la mano?

Que de tan dulces voces al sonido,

Casi con ella me quedé en el cielo.

VOLVIENDO A VALCLUSA AÑOS DESPUES DE LA MUERTE

\section{DE LAURA}

jOh valie donde mi lamento suena,

Río que tonte con mi dloro creces.

Silvestres flores, vagas aves, peces,

Que la una y la otra verde orilla enfrena.

Aura de mis suspiros toda llena,

Dulce senda que amarga hoy me pareces,

Alcor que me alegraste tantas veces

$Y$ ahora me causas tom profunda penal

10

Todos sois lo que fuisteis, todaria;

No yo jay de mil que ton feliz he sido

$Y$ soy albergue de infinito duelo;

Ahl aquí tue donde mi bien vivía, $Y$ desde aquí a los cielos ha subido, Dejando al mundo su terrestre velo. 


\section{VIII}

EN LA MUERTE DE SENNUCIO, POETA Y AMANTE

Aunque quedo sin ti, solo y desierto. Caro Sennucio, al cabo me consuelo; Porque del cuerpo donde estabas muerto Gloriosa tu alma remontó su vuelo.

Ya puedes, lejos de este mundo incierto, Las maravillas contemplar del cielo, $Y$ de mil y mil astros el conclerto;

Yo templo assí con tu placer mi duelo.

- Te ruego que de Venus en la esfera Por mí saludes al divino Dante $Y$ a Beatríz su dulce compañera:

$Y$ dile a Laura que su triste amante, Mientras con ella reunirse espera, en lloro vive $y$ en dolor constante.

\section{Biblioteca de Letras "Jorge Puccinelli Converso" A UN PAIARILLO}

Ave infeliz que, sin un punto ceses,

Lamentas tu fugaz tiempo pasado,

Viendo el infierno lóbrego a tu lado

Y tras de tí el día y los alegres meses.

$\mathrm{Si}$, como sabes tu pescr, supieses

Mi semejante doloroso estado,

Compasivo con este desgraciado

Tus tristes quejas a partir vinieses.

(i) Pajarillo que en voces lastimeras, Vas llorando el infeliz tiempo pasado. Viendo el invierno lóbrego a tu lado $Y$ tras tí las alegres primaveras: (1874). 
Yo no sé si igual fuera nuestre suerte; Que tal vez, la que lloras tiene vida, Cuando a mi Laura, arrebató la muerte.

Mas la hora, la estación y la sentida Queja con que no dejas de dolerte A decirte mis penas me convida.

SEGUNDA SERIE

SONETOS DE DANTE, ARIOSTO, MIGUEL ANGEL Y VICTORIA COLONNA

De Dante ALIGHIERI (1265-1321)

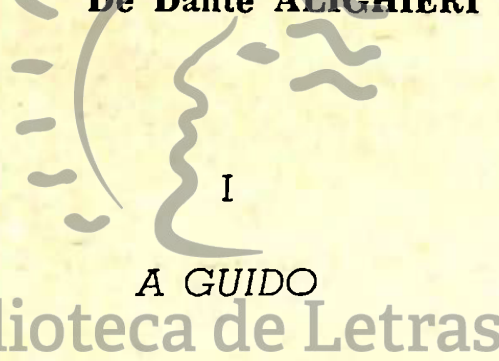

Tú 'Guido, Pulyoicon líapondesearía

Que fuésemos por alto encantamiento Puestos en un bajel que a todo viento A nuestra voluntad bogara y mía.

Y ni mal tiempo o tempestad bravía Nos pudiese causar impedimento, Antes creciese en el común contento El deseo ,de estar en compañía.

Y allí el encantador condescendiente También pudiese a nuestras damas bellas, Beatríz, Juana y la que Safo adora:

Y hablando allí mi amor eternamente, Tan satisfechas cual nosotros ellas, Se nos huyese un siglo como una hora! 


\section{SALUDO A BEATRIZ}

Tan honesta parece y tan hermosa

Mi casta Beatríz cuando saluda,

Que la lengua temblando queda muda Y la vista mirarla apenas osa.

Ella se va benigna y humillosa $\mathrm{Y}$ oyéndose loar, rostro no muda

Y quien la mira enajenado duda

$\mathrm{Si}$ es visión o mujer maravillosa.

Muéstrase tan amable a quien la mira Que al alma infunde una dulzura nueva Que solo aquél que la sintió la sabe:

$$
\infty \text { III }
$$

\section{ALABANZA DE BEATRIZ}

\section{Lleva en isus ojos al amor sin duda}

La que embellece todo lo que mira;

Y tal respeto sulpresencia Ginspirarso,

Que el corazón le tiembla al que saluda.

Dobla él la faz que de color se muda $Y$ sus defectos al sentir suspira;

Huyen ante ella la soberbia e ira;

- Oh bellas, dadme en su loor ayudal

Toda dulzura, toda venturanza

10 nace el alma del que hablar la siente:

Mas, si en sus labios la sonrisa brilla,

(j) Oyendo la alabanza que la endiosa

Ella se va, de vanidad desnuda:

Angel que el cielo por la tierra muda

La juzga quien la vé, no mortal cosa. (1874). 
Se muestran tal, que ni la lengua alcanza Nunca a decir, ni a comprender la mente Tan nueva e increíble maravilla.

\section{A UNA ESTANCIA DONDE ESPERABA A SU AMADA}

\section{De Ludovico ARIOSTO}

\section{I}

¡Venturosa prisión, cárcel suave,

No por amor, no por venganza fiera, $\mathrm{Me}$ tiene la más linda carcelera

A quien es bien que agradecido alabel

Otros cautivos, al sonar la llave, Temen llegada su hora postrimera:

Mas yo me alegro, que el placer me espera, No juez severo, ni sentencia grave.

\section{Biblioteca de Letras}

$\mathrm{Me}$ aguarda el más cortés recibimiento,

Libre plática exenta de embarazos,

Dulces halagos y caricias siento:

De cadenas en vez, floridos lazos, $Y$ besos sabrosísimos sin cuento, Y largos, estrechísimos abrazos.

\section{LA CABELLERA CORTADA}

¿Son éstos los rubísimos cabellos

Que ya bajando en trenzas elegantes, Ya llovidos de perlas y diamantes,

Ya al aura sueltos, eran siempre bellos? 
¡Ahl ¿quien los pudo separar de aquellos

Vivos marilies que ceñían antes,

Del más bello de todos los semblantes,

De sus hermanos más felices que ellos?

Médico indocto, ¿fué el remedio solo Que hallaste, el arrancar con vil tijera Tan rico pelo de tan noble frente?

Pero sin duda te lo impuso Apolo Para que así no quede cabellera Que con la suya competir intente.

\section{A VICTORIA COLONNA}

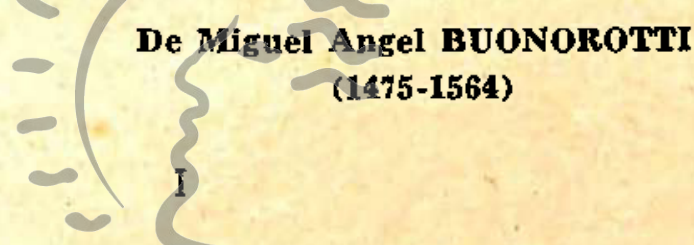

Imposible parece y nos lo advierte

Empero la experiencla que más dura

De mármol insensible uno figura

Que su autor, presa en breve de la muerte.

Más que la causa es el efecto fuerte, Por el arte es vencida la natura:

Lo se yo a quien da gloria la escultura,

Y ya me acerco a la vejez inerte.

Tal vez a tí y a mi dar larga vida

10 Puedo con el cincel o los colores,

Adunando mi amor y tu semblante.

Y mil años después de la partida,

Se verón tus hechizos vencedores,

Y cuánta razón tuve en ser tu amante.

(k) Que su Hacedor que hiere pronta muerte. (1874). 
II

\section{DESENGANO}

Llegó ya el curso de la vida mía

Por lempestuoso mar, en frágil barca,

Al común puerto, en el que se da parca

Cuenta de toda acción, injusta o pía.

¡Cuánto ello la amorosa fantasía

Que del arte hizo su ídolo y monarcal

Que en cuanto alumbra el sol y el mar abarca

Es todo error cuanto el mortal ansía.

Devaneos de amor, triunfos del arte,

¿Qué sois, hoy que a dos muertos me avecino?

Una es segura, la otra me amenaza.

No habrá pintar, no hay esculpir que hoy harte

Al alma vueltar ar aquel amor divino

Que de la cruz al universo abraza.

\section{Biblioteca Ile Letras "Jor ALLLCARPEFNALE BEMESON"}

\section{De Victoria COLONNA (1492-1547)}

$\mid$ Ay $\mid$ cuanto fuí a mi sol (*), contrario al hado

Que antes el numen con su rayo ardiente

No os encendió, para que eternamente

Fuérais más claro vos, el más loadol

Con vuestro estilo noble y levantado

entre todos famoso y excelente

Su nombre hubiérais del ocaso a oriente

De la segunda muerte preservado.

(*) Dice esto porque Apolo o Febo era al par Dios de la poesía y de la Medicina y Padre de Esculapio. Con el nombre de sol designaba Victoria Colonna a su difunto esposo, el Marqués de Pescara. (Nota de Althaus). 
„Pudiese daros yo el ardor, que siento, O vos a mí la inspiración suprema. Para cantar un mérito tan nuevo.

Mas al cielo dejamos descontento Vos porque no escogísteis ese tema. Yo porque de tal sol a hablar me atrevo.

De mi sol claro, con la muerte ciego, Aquí miro doquier las dulces huellas; ciego no; más allá de las estrellas Arde con luz más clara y vivo fuego. Biblioteca de Letras

Aquí vencido de mi dimante ruego,rso"

El me mostró sus cicatrices bellas, Y yo mis labios estampaba en ellas, $Y$ las bañaba de mi llanto el riego.

Sus brillantes victorias me contaba Y el modo y la ocasión con la serena Faz con que abría la contienda brava :

De llanto rompo en dolorosa vena, Pues lo mismo que un tiempo me alegraba Me causa ahora inconsolable pena. 
TERCERA SERIE

\section{A ITALIA}

Del Cardenal Pietro BEMBO

(1470-1547)

Oh tú del mundo la más bella parte,

Que cin̄e el vasto mar y el Alpe cierra,

Oh dulce, alegre, deleitosa tierra;

Que alto y soberbio el Apenino parte:

En vano el pueblo te dejó de Marte

Señora de la mar y de la tierra:

Hoy tus antiguas siervas te hacen guerra

Y no cesan de herirte y de pegarte.

Ni folta entre tus hijos quien ajeno

Poder devastador convide y llame

Y hunda su espada en tu materno seno:

No queda ya quien te respete y ame;

Oh duro siglo de maldades lleno:

Oh estirpe vil, degenerada, infame!

A SAN FRANCISCO DE ASIS

De Torcuato TASSO (1544-1595)

I

IOh tú a quien Cristo con su propia mano En el cuerpo imprimió las hondas huellas De las llagas sangrientas cuanto bellas

Que recibió en el leño soberonol

9 Pues, ya, a tu pío Salvador cercano

Resplandecer las miras cual estrellas, No dejes que la voz de mis querellas

A sus oídos se levante en vano. 
Sus golpes para mí son tan violentos

10 Como suaves para tí las llagas;

Estas eran de amor, esos son de ira;

- Mas tú me los endulzas; tú me inspiras Tanto tu puro ardor que con él hagas Que en Dios hallé felices mis tormentos.

II

COMPARA SU AMADA A LA AURORA

Cuando sale la Aurora y su faz mira

En el espejo de las ondas; siento

Las verdes hojas susurrar al viento;

Como en mi pecho el corazón suspira.

5 También busco mi aurora; y si a mí gira

Dulce mirada, muero de contento;

Veo los nudos que en huir soy lento

$Y$ que hacen que ya el oro no se admira.

Mas al sol nuevo en el sereno cielo

10 No derrama madeja tan ardiente

La bella "amiga de Titón celoso pnverso"

Como el dorado rutilante pelo

Que orna y corona la nevada frente

de la que hurtó a mi pecho su reposo.

A UNA DONCELLA QUE PROFESABA

De Vincenzo MONTI (1754-1828)

I

El día que en tu faz la gloria entera

Del grande sacrificio fulguraba

y una luz de los cielos hechicera

En tus ojos extática brillaba, 
A tu oído la queja lastimera

De tu doliente Juventud sonaba

Y sobre tu cortada cabellera

La despreciada Libertad Lloraba.

El placer lisonjero te ofrecía

Sus deleites funestos y a la enirada

Con mano cudáz tu veste removía;

Mas tú las puertas, invencible y fuerte,

Cerraste de tu mística morada

$Y$ le diste las llaves a la Muerte!

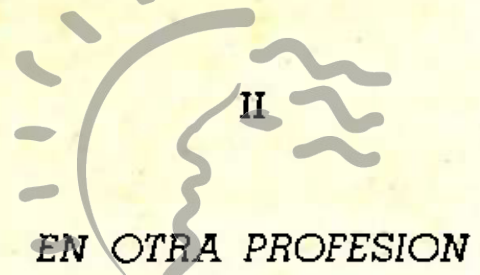

Oh Bibertadi tiOh de héroes máare santa,

Y dejlos hombres principa! derecho,

Que está grabado en todo noble pecho

$Y$ nuestra parte superior levanta!

¿Pues cómo así con atrevida planta

$\mathrm{Te}$ deja incauta virgen $\mathrm{y}$ su techo

Nativo trueca por el claustro estrecho

$Y$ eterno cautiverio no la espanta?

Mas no; que, aunque parece que te huella

10 Al hierro dando su dorado pelo,

Quien más te busca, Libertad, es ella:

Más libre la hace su ceñido velo, porque la misma servidumbre es bella Si eterna Libertad nos da en el cielo. 


\section{A ITAIIA}

De Vincenzo Da FILICALA (1642-1704)

Italia, Italial oh tú a quién dió la suerte el don fatal de la beldad y en ésta De mil males y vil dote funesta:

Oh! menos bella fueras ó más fuerte!

Así o lograras invencible hacerte

O no tentaras con tu luz modesta

Ia codicio de aquel que te detesta

Fingiendo amarte; y que te reta a muerte.

No viera el Alpe entonces mil torrentes De armados galos derramar do quiera $\mathrm{Y}$ que tu noble sangre el Pó coloral

$\mathrm{Ni}$ por el brazo de extranjeras gentes Inútilmente combatir, te viera, Para servir, vencida o vencedora.

\section{Biblioteca de Letras "Jorge AMI MFRMANO}

De Hugo FoscoLo (1778-1827)

Un dia, sino fuera siempre huyendo me sentaré en tu tumba con agudo Dolor, Oh hermano de mi amor, gimiendo Que tan joven hallaras fin tam crudo.

Sola hoy la Madre, lágrimas vertiendo. Habla de mi con tu cadóver mudo; Mas yo ambos brazos vanamente os tiendo $Y$ de lejos mi dulce hogar saludo. 
Siendo tus mismos males torticeros, $Y$ al puerto pido paz do le acogiste. Ya fatigado de estos mares fieros.

Es la última esperanza que me asiste: ISiquiera mis huesos, píos extranjeros. Volved al pecho de la madre tristel

\section{II}

\section{A LA AMADA}

Así el entero día en largo, incierto Sueño gimo: mas luego cuando aduna La noche las estrellas y la luna, Frío el aire y de sombras ya cubierto.

Donde el llano es selvoso y más desierto Lento entonces vagando, una por una, Palpo las llagas que la vil fortuna $Y$ Amor $\mathrm{y}$ el mundo han en mi pecho abierto.

Tal vez cansado, apoyo me dá un pino O con mis esperanzas, ilíodondeso" Suena la onda, tal vez hablo y deliro.

Mas las iras del mundo y del destino Olvidando por tí, por tí suspiro Luz de mis ojos, quién a mí te esconde?

\section{LOS TREINTA Y CINCO ANNOS}

\section{De GIUSEPPE GIUSTI (1809-1850)}

Ya tengo treinta y cinco, y desterrada

Está del todo la locura mía:

O si un grano me queda todavía Por algún pelo blanco está templada : 
Conmlgo vida menos agitada

De media prosa y media poesía

Vida de estudio y plácida alegría,

Mundana en parte, en parte retirada.

Y prosiguiendo con la danza aquesta

10 Viendo temas de risa por doquiera,

Vendrá la muerte a concluir la fiesta:

Moriré alegre, si mi vida entera

Mereciese una lápida modesta

Que lleve escrito "No mudó bandera".

Para permitir la comparación entre las dos versiones peIrarquianas de Althaus con las de Garcés, publicamos a continuación las de éste último en paralelo con los textos italianos originales de Petrarca.

Nos hemos servido de la edición principal de Garcés (Los Sonetos y Canciones del poeta Francesco Petrarcha, Madrid, en la casa de Gmo. Droy, 1591) y la edición crítica de las obras de Petrarca. Le Rime Di MolFrancescoi Petrárco Ilustrate con note dal P. Francesco Soave C.R.S., Milano, Dalla Societá Tipográfica de Classia Italians, 1805, 2 vols. 